Expression of Affect and the Emergence of Language Author(s): Lois Bloom and Joanne Bitetti Capatides

Source: Child Development, Vol. 58, No. 6 (Dec., 1987), pp. 1513-1522

Published by: Wiley on behalf of the Society for Research in Child Development

Stable URL: http://www.jstor.org/stable/1130691

Accessed: 26-01-2017 19:00 UTC

\title{
REFERENCES
}

Linked references are available on JSTOR for this article: http://www.jstor.org/stable/1130691?seq=1\&cid=pdf-reference\#references_tab_contents You may need to $\log$ in to JSTOR to access the linked references.

JSTOR is a not-for-profit service that helps scholars, researchers, and students discover, use, and build upon a wide range of content in a trusted digital archive. We use information technology and tools to increase productivity and facilitate new forms of scholarship. For more information about JSTOR, please contact support@jstor.org.

Your use of the JSTOR archive indicates your acceptance of the Terms \& Conditions of Use, available at http://about.jstor.org/terms

Society for Research in Child Development, Wiley are collaborating with JSTOR to digitize, preserve and extend access to Child Development 


\title{
Expression of Affect and the Emergence of Language
}

\author{
Lois Bloom and Joanne Bitetti Capatides
}

Teachers College, Columbia University

\begin{abstract}
Bloom, Lois, and Capatides, Joanne Bitetti. Expression of Affect and the Emergence of Language. CHILD DEVELOPMENT, 1987, 58, 1513-1522. The relation between infant affect expression and the emergence of language was studied in 6 girls and 6 boys, from 9 months to 2 years of age. First words (FW) and vocabulary spurt (VS) were identified in the infants' transition from prespeech vocalizing to the emergence of language. Their expressions of affect were coded for the gradient properties of valence (positive, negative, neutral, mixed, equivocal) and intensity. Frequency of nonneutral affect expression at FW and VS was positively correlated with age at FW and VS ( $p<$ .02), meaning that the more frequently the children expressed emotion, the older the age of language achievements. Time spent in neutral affect at FW and VS was negatively correlated with age at FW and VS $(p<.02)$; the more time spent in neutral affect, the younger the age of language achievements. In addition, the measures of affect at VS predicted the eventual transition to multiword speech, with more time spent in neutral affect expression at VS negatively correlated with earlier age in the use of sentences. We propose that neutral affect supports the early transition to language by allowing the reflective stance required for language learning, and has its antecedents in the quiet alert states which support the cognitive activity of early infancy.
\end{abstract}

The two systems of expression, affect and speech, have different developmental histories. Some expressions of affect are present virtually from birth (e.g., Darwin, 1913; Izard, Huebner, Risser, McGinnes, \& Dougherty, 1980), and much of the form and content of communication between infants and their caregivers in the first year of life depends upon affective expression (e.g., Dore, 1983; Emde, Gaensbauer, \& Harmon, 1976; Lock, 1978; Stechler \& Carpenter, 1967; Stern, 1977). In contrast, the forms of speech have to be learned, and children usually begin to acquire words in the second year. The purpose of this study was to determine how affect expression relates to learning words in the period of transition from prespeech infancy to the emergence of language.

Given the temporal precedence of affect for communication, the expression of emotion might be expected to facilitate learning words. Indeed, among the classic phylogenetic theories of language are those that appeal to the expression of feelings and emotions for the origins of words. In the most influential of these theories, Condillac, in the eighteenth century, proposed that the conventional signs of speech originated when the involuntary vocal gestures that expressed "the passions of joy, of fear, or of grief" were deliberately repeated in the absence of their reflexive eliciting conditions for the benefit of others (cited in Aarsleff, 1976, p. 10). These theories are echoed in contemporary ontogenetic accounts that trace the origins of language for communication to affective exchanges between infants and their caregivers. The first hypothesis tested in the present study built upon the developmental precedence of affect for communication. This hypothesis, the emotionality hypothesis, was that the frequency with which infants display positive and negative emotion would predict $(a)$ early emergence of words and $(b)$ frequency of expression with words.

The second hypothesis built upon differ-

We are grateful for the support received from the Spencer Foundation for the conduct of this research, and we thank Richard Beckwith, Jeremie Hafitz, Karin Lifter, and Matthew Rispoli for their considerable involvement in all phases of the project. We thank Rick Booth, Abdul Raquib, and Donald Albury for their technical assistance; Margaret Honey, Tresmaine Roubaine, and Joy Vaughn for their assistance in data collection; Virginia Brennan, Suzanne Gottlieb, Geraldine McDonald, Marriete Newton-Danilo, Lisa Spiegel, Joy Vaughn, and Pia Wikstrom for their assistance in data transcription and coding; and Kathleen Bloom, Karin Lifter, and Carol Malatesta for their insightful comments and suggestions after reading an earlier draft of this paper. Our warmest appreciation goes to the children, for sharing their development with us, and their mothers, for their uninterrupted participation in the project. Requests for reprints should be addressed to Lois Bloom, Box 5, Teachers College, Columbia University, 525 West 120th Street, New York, NY 10027.

[Child Development, 1987, 58, 1513-1522. () 1987 by the Society for Research in Child Development, Inc. All rights reserved. 0009-3920/87/5806-0012\$01.00] 


\section{Child Development}

ences in the cognitive requirements for learning words and expressing emotion, and the difference between them in underlying stance. Words are arbitrary units that have to be learned, and words require a reflective stance. The mental representations that underlie linguistic actions of expression and interpretation are constructed from aspects of knowledge recalled from memory and the data available in perception (Bloom \& Beckwith, 1986). Language emerges in the child's endeavor to recall and recognize words that express these mental contents, and this endeavor entails cognitive effort (Bloom, 1981).

The expression of affect is automatic and effortless $(a)$ being virtually a symptom of the emotion it is an expression of, and $(b)$ having been in place since early infancy. Underlying an expression of affect is an evaluative stance-one in which the individual evaluates the situation in relation to existing contents of a mental state (e.g., Sroufe, 1984; Wozniak, 1986). The cognitive component of an emotion is often the evaluation of the situation in relation to some goal (e.g., Campos, Barret, Lamb, Goldsmith, \& Stenberg, 1983; Stein \& Jewett, 1986).

The evaluative stance underlying emotions and the expression of positive and negative affect could preempt the resources needed for learning words. However, neutral affect would allow the reflective stance required for the effort of accessing memory for the contents of mental states that underlie both expression and interpretation for learning words. The second hypothesis tested in this study, the reflectivity hypothesis, was that the time spent in neutral affect states would be associated with early achievements in learning words.

\section{Method}

Twelve infants were subjects in a longitudinal investigation from 9 months to 2 years of age. ${ }^{1}$ The infants, six girls and six boys, came from homes in the New York metropoli$\tan$ area, and were of mixed ethnicity and socioeconomic background. Each infant and mother visited our laboratory playroom once each month from about 8 months to about 28 months of age and played with groups of toys that were introduced on a schedule, at 8-min intervals. All of the children were presented with the same groups of toys in the same se- quence, and a snack after the first half hour. Each session lasted 1 hour. The children were also visited at home every month until they were 15 months old, and then every 3 months thereafter.

The playroom observations were videorecorded in stereo, and a SMPTE time-code generator imposed a discrete, computerreadable auditory signal on the second sound track of each frame of the tape. This allowed the data to be manipulated to within onethirtieth of a second (each second of videotape containing 30 frames) at the time of data processing. The videotape deck was interfaced at playback with a SMPTE time-code reader and an Apple II plus computer for data coding and transcription.

Three playroom observations from each child provided the data for the study reported here. These were the reference points used to define the period of transition to language. The first was the same for all of the children, the prespeech observation at 9 months, before words emerged. The second and third were different for the individual children and determined by each child's progress in lanSguage. The second was the month when each child reached the criterion for "first words" (FW): the first use of at least one conventional word, said at least two times. The FW observation was the reference point for the beginning of the transition into language. The third reference point was a "vocabulary spurt" (VS), the first increase of at least 12 new words (utterance types) after the child had already acquired at least 20 different words. This month was the reference point for what we considered to be the end of the transition period. Any conventional words, including parts of routines and interjections, were counted for identifying the FW and VS language achievements, but imitations of mothers' speech and self-repetitions were not. The two reference points-beginning to say words and a sharp increase in the number of words-have long been considered major developments defining the transition to language in the single-word period (e.g., Bloom, 1973; Dromi, 1982; McCarthy, 1954; Nelson, 1973; Stern \& Stern, 1907). Mean age at FW was 13.6 months (range $=305-510$ days) and mean age at VS was 19.6 months (range = 392-755 days).

\footnotetext{
${ }^{1}$ Fourteen subjects participated in the research project of which this study is a part; however, data collection was begun with two of the children later than 9 months, so that the prespeech comparisons reported here were not possible. For this reason, the present study includes only those children for whom data were available beginning at 9 months.
} 
Speech and affect expression were each transcribed and coded independently by different persons. Coders were naive both to the hypotheses to be tested and the units of analysis in the study.

Speech transcription.-Two transcription passes were made through the data to assure reliability. The first transcription of the children's words (and all other nonword vocalizations in the FW observation) was originally written out by hand, with nonword vocalizations and questionable words transcribed phonetically. A second transcriber then entered the words and vocalizations into the computer with times of onset and offset, using the original transcription while reviewing the video record. Differences between transcribers in identifying words were resolved by having both review the tape together; when agreement could not be reached, the vocalization was discounted as a word and not included in the analyses.

Affect coding.-The emotional signal carries both categorical and gradient information (Stern, Barnett, \& Spieker, 1983). Categorical information is the particular emotion (such as anger, joy, or sadness) that is expressed. We are unaware of any explicit theoretical or empirical claims for the relation of the discrete emotions to the emergence of language. For this reason, a coding scheme was devised to capture the gradient properties of affective expression, valence (hedonic tone), and intensity, and discrete categories of emotions were not identified or labeled. (See Adamson \& Bakeman, 1982; Ricciuti \& Poresky, 1972; and Stechler \& Carpenter, 1967, for other studies that used gradient information in the study of affect.)

Every change in expressed affect in the stream of the child's activities was identified in the first half hour of the observations at 9 months, FW, and VS, and entered into the computer with the time of onset. The onset time of any change in affect expression was the offset time of the previous affect expression. This yielded a continuous record of $(a)$ affect expressions and $(b)$ the duration of affect expressions from one shift in expression to another. An affect expression was any observable change in either valence or intensity (using as cues the child's facial expression, body tension or posture, and affective vocalizations such as whining, laughing, and the like).

These affect expressions were coded for their valence, whether neutral, negative, positive, mixed, or equivocal hedonic tone. A neutral expression was defined by the face being in a resting or baseline position, as described by Ekman and Friesen (1975), and without body tension or affective vocalization. Mixed affect was an expression that included elements of both positive and negative valence; equivocal affect was neither positive, negative, nor neutral, as happened with expressions of surprise or excitement. Nonneutral affect expressions were also coded for intensity with three levels of intensity indicating the fullness of a display. Thus, the coding scheme for describing the quality of expressed affect included three levels of intensity: 1, 2, 3, and 5 qualities of valence: neutral, negative, positive, mixed, and equivocal. (See Bloom, Beckwith, Capatides, \& Hafitz, 1987, for photographs of examples of these affect expressions.)

Ambiguous cases (the occurrence of a momentary vocalization or facial movement that could not be assigned to one of the above categories) were also coded with time of onset. These were less frequent at VS (mean = $10.7)$ and 9 months (mean $=15.4$ ) than at $\mathrm{FW}$ (mean $=19.8)$; they were not included in the data analyses. In addition, the child was sometimes moving away from the camera, or the child's face was not visible for affect coding with no cues from body tension or affective vocalization. These intervals of "backturn" were coded for onset so that coding affect expression in the stream of the child's activity was not interrupted. (The coding scheme used in this study is available from the authors.)

Three coders initially worked in rotating pairs during training, in order to increase the accuracy of coding and to ensure initial confidence in their judgments. Training continued until the paired coders (the three coders each rotated with one another) achieved a predetermined level of at least $85 \%$ agreement with a precoded segment of data, considered as a standard, that was coded by the investigators responsible for training. Segments were selected randomly from different children for this posttraining test of reliability, and each segment lasted from 2 to $5 \frac{1}{2} \mathrm{~min}$. Percent agreement was computed separately for the categories of valence (positive, negative, neutral, mixed, and equivocal) and for the intensity (one, two, and three degrees) of all of the categories of nonneutral valence. This level of reliability for the coder pairs, after training and before the actual coding for the study was begun, was high: for valence, Pair $1=92 \%$, Pair $2=90 \%$, Pair $3=100 \%$; and for intensity, Pair $1=89 \%$, Pair $2=89 \%$, and Pair 3 $=85 \%$. 


\section{Child Development}

After continuing to code in pairs for several weeks, reliability was assessed for the individual coders working independently in the following way. Each individually coded a $3 \frac{1}{2} 2^{-}$ min segment that included at least 25 coding entries. The percent agreement between each member of a pair coding independently was high: Pair $1=100 \%$; Pair $2=94 \%$; and Pair $3=94 \%$ for both valence and intensity. At that point the coding was begun for the data used in this study, with the coders working independently.

The margin of error for affect onset time was 16 video frames, or approximately $1 / 2 \mathrm{sec}$, which was the mean discrepancy in coding onset time among the three coder pairs. Because affect was coded continuously, the onset time of an affect expression was the offset time of the previous expression. The margin of error for onset time of an affect expression was somewhat greater than the onset and offset times for speech, due to the fact that several kinds of continuous cues were used to code affect (i.e., facial expression, body tension, affective vocalization). For transcription of speech (and all nonspeech vocalizations at FW) the margin of error for onset and offset times was computed by having two independent transcribers judge the times of word onset and offset for a sample of 100 words, in blocks of 10 , from different children selected at random, half at FW and half at VS. The margin of error for word onset time was within two video frames (or $1 / 15 \mathrm{sec}$ ) in $92 \%$ of the judgments of the two independent coders, and within five video frames (or $1 / 6 \mathrm{sec}$ ) in $82 \%$ of their judgments for word offset time.

The processed data were transferred to an IBM-XT computer for analyses. The coded affect was reduced using a program that $(a)$ counted all affect expressions (including intensity shifts, e.g., from +1 to +2 , or from -2 to -1$) ;(b)$ counted the number of frames for the duration of each affect expression; and (c) calculated the mean duration and total time spent in 10 categories of affect expression: three degrees of positive valence; three degrees of negative valence; neutral, mixed, and equivocal valence; and ambiguous cases.

Data analyses. - The two principal measures of affect that were used to test the hypotheses in this study were the percentage of total time (in frames) that the infants spent in neutral expression, and the frequency of their nonneutral affect expressions. Time in neutral states rather than frequency of neutral expressions was used in the analyses for two reasons. For one, the frequency of shifts into neutral states was conditioned by the fre- quency of nonneutral expressions (i.e., the shifts into $+1,-2$, etc. were often shifts from neutral and followed by shifts back into neutral). More important, the reflectivity hypothesis was predicated on the assumption that time in neutral was required for learning words. The frequency of affect expressions was the primary measure of nonneutral affect because the emotionality hypothesis was predicated on the assumption that frequent expression of emotion would facilitate learning words. The percentage of time the infants spent in nonneutral affect was not a separate measure since it was the inverse of the time they spent in neutral affect.

Secondary measures of affect were $(a)$ the mean duration of neutral affect expressions, (b) the percentage of time spent in positive and negative affect expressions, and $(c)$ the frequency of positive and negative expressions.

The first analysis was a description (means and standard deviations) of the two principal affect measures: percentage of total time spent in neutral affect and frequency of nonneutral affect expressions. Both measures were then correlated between 9 months, FW, and VS to determine their stability in this period.

In order to test the emotionality hypothesis-that frequency of emotional expression would predict emergence and frequency of words-the frequency with which the infants expressed nonneutral affect at FW and VS was correlated (Pearson) with $(a)$ age at FW and VS and $(b)$ the frequency of words at FW and VS. Secondary analyses of both frequency of expressions and measures of time were used to compare the separate effects of positive and negative affect.

To test the reflectivity hypothesis-that neutral affect would be associated with early achievements in learning words-the percentage of time spent in neutral affect at FW and VS was correlated with $(a)$ age of FW and $\mathrm{VS}$, and $(b)$ the frequency of words at FW and VS.

In addition, measures of affect at FW and VS were correlated with the age at which the children eventually reached the transition to multiword speech, to test whether affect in the period of word learning predicted the beginning of word combinations. The criterion for the transition to multiwords was a mean length of utterance of 1.5 words, discounting imitations, self-repetitions, bound morphemes, "yeah" and "no," and the articles "a" and "the" (after Rispoli, 1986). 
TABLE 1

Means and Standard Deviations for Age and Affect Measures $(N=12)$

\begin{tabular}{|c|c|c|c|}
\hline & 9 Months & First Words & $\begin{array}{l}\text { Vocabulary } \\
\text { Spurt }\end{array}$ \\
\hline \multicolumn{4}{|l|}{ Age (days): } \\
\hline Mean... & 274.75 & 408.58 & 588.08 \\
\hline $\mathrm{SD} \ldots \ldots \ldots \ldots \ldots \ldots \ldots \ldots$ & 6.0 & 56.7 & 108.26 \\
\hline \multicolumn{4}{|c|}{ Frequency of emotional expressions: } \\
\hline Mean $\ldots \ldots \ldots \ldots \ldots \ldots \ldots \ldots$ & 49.17 & 72.58 & 75.33 \\
\hline SD $\ldots \ldots \ldots \ldots \ldots \ldots \ldots \ldots \ldots$ & 31.43 & 37.05 & 24.49 \\
\hline \multicolumn{4}{|l|}{ Percentage of time in neutral states: } \\
\hline Mean ..................... & .869 & .846 & .823 \\
\hline $\mathrm{SD} \ldots \ldots \ldots \ldots \ldots \ldots \ldots \ldots$ & .096 & .077 & .079 \\
\hline
\end{tabular}

\section{Results}

The affect measures.-The means and standard deviations for age and the two principal affect measures, frequency of emotional expression and percentage of time in neutral affect expression, are presented in Table 1. The large variability in age and frequency of emotional expression reflected individual differences among the children in the development of affect from 9 to 21 months (reported in Bloom, Beckwith, \& Capatides, 1987).

The differences among the infants were stable in the period from FW to VS, but not between 9 months and either of the two language achievements, as can be seen in Table 2 ; both measures were significantly correlated between FW and VS $(p<.05)$. This means that frequency of emotional expression and time spent in neutral affect were stable for the individual children in the period during which words were emerging, but not before.

The children were expressing neutral affect, on average, $84 \%$ of the time. When they were expressing nonneutral affect, that affect was positive most often. The mean proportion of time spent in positive affect varied from .099 (9 months), to .125 (FW), to .146 (VS). The mean proportion of time in negative affect remained the same: $.030, .026$, and .028 at 9 months, FW, and VS, respectively.
The two principal affect measures, frequency of emotional expression and percentage of time in neutral affect, were highly and negatively correlated with one another, $r(10)$ $=-.941,-.943,-.810$ at 9 months, $\mathrm{FW}$, and VS, respectively. Although the information provided by these two measures was somewhat redundant, the two measures together were more descriptive than either one alone.

The emotionality hypothesis.-The results of the analysis to test the hypothesis that frequency of emotional expression would be associated with age of language achievement are presented in Table 3. These correlations of frequency of emotional expression and age at FW and VS were all in the positive direction and statistically significant at the .05 level or less. Thus, the more frequently the children expressed their emotions, the older they were at the time of the language transitions.

The infants' emotional expressions were positive affect $78 \%$ of the time, on average. Frequency of positive expressions also correlated with age at $\mathrm{FW}, r(10)=.608, p=$ .036 , and VS, $r(10)=.613, p=.034$, but the frequency of negative expressions did not. Using time (in frames) as a measure, the percentage of time spent in positive affect also correlated with age at FW, $r(10)=.664, p=$ .019 , and VS, $r(10)=.765, p=.004$, but the percentage of time spent in negative affect

TABLE 2

Correlations (Pearson $r$ ) of Affect Measures between Language AChievements $(N=12)$

\begin{tabular}{|c|c|c|c|}
\hline \multirow[b]{2}{*}{ Affect Measures } & \multicolumn{3}{|c|}{ LANGUAGE ACHIEVEMENTS } \\
\hline & 9, FW & $9, \mathrm{VS}$ & $\mathrm{FW}, \mathrm{VS}^{\mathrm{a}}$ \\
\hline $\begin{array}{l}\text { Frequency of emotional expression } \ldots \ldots \ldots \ldots \\
\text { Percentage of time in neutral states } \ldots \ldots \ldots \ldots\end{array}$ & $\begin{array}{l}.307 \\
.074\end{array}$ & $\begin{array}{l}-.070 \\
-.136\end{array}$ & $\begin{array}{l}.636(p=.026)^{\mathrm{b}} \\
.640(p=.025)\end{array}$ \\
\hline
\end{tabular}

\footnotetext{
${ }^{a} \mathrm{FW}=$ first words; VS = vocabulary spurt.
}

b $10 \mathrm{df}$, two-tailed test. 
TABLE 3

Correlations (Pearson $r$ ) of Frequency of Emotional EXPRESSION WITH AGE AT FIRST WORDS AND VOCABUlaRY SPURT $(N=12)$

\begin{tabular}{|c|c|c|}
\hline \multirow{2}{*}{$\begin{array}{c}\text { FREQUENCY OF } \\
\text { EMOTIONAL } \\
\text { EXPRESSION }\end{array}$} & \multicolumn{2}{|c|}{$\begin{array}{l}\text { AGE AT LANGUAGE } \\
\text { ACHIEVEMENTS }\end{array}$} \\
\hline & Age FW & Age $V^{a}$ \\
\hline $\begin{array}{c}\text { First words . } \\
\text { Vocabulary } \\
\text { spurt..... }\end{array}$ & $\begin{array}{l}.658(p=.020)^{\mathrm{b}} \\
.662(p=.019)\end{array}$ & $.593(p=.042)$ \\
\hline
\end{tabular}

${ }^{\mathrm{a}} \mathrm{FW}=$ first words; VS = vocabulary spurt.

${ }^{\mathrm{b}} 10 \mathrm{df}$, two-tailed test.

did not. These results mean that the relation between frequency of emotional expressions and later age of language achievement was dependent on positive affect primarily.

The reflectivity hypothesis.-The results of the analysis to test the hypothesis that time in neutral affect would be associated with early age of language achievements are presented in Table 4. The correlations of age at FW and VS with percentage of time spent in neutral expression, at FW and VS, respectively, were in the negative direction and significant, $r(10), p<.02$. The children who spent more time in neutral affect showed earlier achievements in word learning.

An additional measure was the mean duration of neutral expressions, which was how long a neutral expression lasted on average. Early word learning was significantly correlated with longer neutral expressions. A problem in reporting this result, however, was that the mean duration of neutral expressions covaried with the amount of time the infants had their backs to the camera or were otherwise not available for affect coding. Thus, this measure was not appropriate empirically, although it is, at least potentially, an appropriate measure conceptually.
Frequency of words.-In the second test of the emotionality and reflectivity hypotheses, the numbers of words (both utterance tokens and types) were correlated at FW and VS, and with (a) frequency of emotional expression and $(b)$ the percentage of time spent in neutral affect at FW and VS. None of the correlations was significant. A regression analysis to test the interaction between frequency of emotional expression and age at FW, with the number of word types at FW as the dependent variable, was not significant, $F(2,9)=2.679, p=.122$.

The transition to multiword speech.-At the children's eventual transition to multiword speech (mean length of utterance $M=$ $1.50, \mathrm{SD}=.111)$, their mean age was 24.23 months $(\mathrm{SD}=4.25$, range $=514-960$ days $)$, and the mean span between VS and the transition to multiword speech was 4.63 months (SD $=1.28$, range $=76-210$ days). The affect measures at VS predicted age of multiword speech: frequency of emotional expression, $r(10)=.668, p=.018$, and percentage of time in neutral affect, $r(10)=-.711, p=$ .009. While not significant, the correlations with the affect measures at FW and age of multiword transition were high, for example,

TABLE 4

Correlations (Pearson $r$ ) OF Time in

Neutral AfFect with Age at First Words AND VOCABULARY SPURT $(N=12)$

\begin{tabular}{|c|c|c|}
\hline \multirow{2}{*}{$\begin{array}{l}\text { PERCENTAGE } \\
\text { OF TIME IN } \\
\text { NEUTRAL } \\
\text { EXPRESSION }\end{array}$} & \multicolumn{2}{|c|}{$\begin{array}{l}\text { AGE AT LANGUAGE } \\
\text { ACHIEVEMENTS }\end{array}$} \\
\hline & Age FW & Age VS ${ }^{a}$ \\
\hline $\begin{array}{l}\text { First words } \ldots \ldots \\
\text { Vocabulary } \\
\text { spurt ........ }\end{array}$ & $\begin{array}{l}-.697(p=.012)^{\mathrm{b}} \\
-.522(p=.082)\end{array}$ & $\begin{array}{l}-.578(p=.049) \\
-.828(p=.001)\end{array}$ \\
\hline
\end{tabular}

FW = first words; VS = vocabulary spurt.

b $10 d f$, two-tailed test. 
percentage of time in neutral affect, $r(10)=$ $-.538, p=.071$. Early age of transition to multiword speech was predicted by more time in neutral affect at VS, and more frequent emotional expression at VS predicted later age of transition to multiword speech.

\section{Discussion}

One of the most frequently cited facts of child language is that children differ widely in onset and rate of language development. In the present study, such differences were associated with differences in the quality of expressed affect. Language emerges in the child's endeavor to recall and recognize words that express the contents of their mental states. Such cognitive activity requires a reflective stance, one which, we suggest, would be more likely to occur with neutral affect than with expression of the positive and negative emotions. For the children in this study, more time spent in neutral affect was associated with early language achievements. The more time the children spent in neutral affect, the younger they were at the time of FW and VS, and more time spent in neutral affect at VS predicted earlier transition to multiword speech.

We propose that the neutral affect we have described here has its antecedents in the "quiet alert states" during which neonates and young infants attend to visual and auditory stimuli (e.g., Brazelton, 1979). These quiet alert states are initially brief and occur rarely, but they increase in frequency and duration with development. They are generally considered to be the moments during which infants are perceiving and learning from objects and events in their environments (e.g., Lamb \& Campos, 1982; Olson \& Sherman, 1983). Just as quiet alert states support the cognitive activity of the younger infant, neutral affect supports the cognition required for early word learning in the transition to language in the second year.

Both neutral affect at the age range studied here and the quiet alert states of early infancy are relevant to the emotions category of "interest." Interest was considered to be a source of energy in the creation of new cognitive structures by Piaget (1954/1981), and interest was described as an "organizer and motivator of attention" by Izard (1986, p. 27). These views are compatible with the claim we are making for the importance of neutral affect for language learning. And indeed, the neutral affect expression coded in this study included expression of the emotions category of interest (C. Malatesta, personal communi- cation). Several convincing arguments against the notion that interest is a discrete emotion were put forth by Wozniak (1986), and we suggest that interest is part but not all of what was coded here as neutral affect. The category of neutral affect needs to be explored further in future research, accounting as it did for such a large proportion of the children's affect expression. One thing was clear, however; neutral affect was not "flat affect." The infants in neutral states were best described as quiet, alert, and attentive.

Although the neutral affect described here has its antecedents in the quiet alert states of early infancy, the affect measures at 9 months were not correlated with the measures at FW and VS. This long-term discontinuity was probably the result of the considerable variability among the infants in the length of time that elapsed between 9 months and VS (range $=4$ to 16 months). One possible explanation of the stability from FW to VS is that learning to say words may have a stabilizing effect on emotional expression. Given that affective communication is in place from early infancy, learning language entails a shift in attentional resources. Change in one domain (i.e., language) may require stability in another (i.e., emotionality) (Bloom \& Wickstrom, 1987). Other evidence of stability in the children's affect expression between FW and VS was reported in Bloom et al. (1987).

The children in this study differed in their expression of affect, and these differences were reflected in the emergence of language. Because the subject population included only 12 subjects, formal tests of group differences were not possible. However, we can report that children of both sexes, and different ethnic and economic backgrounds, were among the children who expressed emotion frequently and talked later, and also among the children who spent relatively more time in neutral affect and talked earlier.

The emotionality hypothesis was not supported. Frequency of emotional expression was not significantly correlated with number of words at FW or VS. Further, emotional lability was associated with later age of language achievements, suggesting that emotional expression does not facilitate early language learning.

Two points deserve emphasis in interpreting these results. The first is that we are not talking here about language delay. All of the infants reached the FW and VS achievements, and none were at risk for language disorders in this period. Several factors could 
have contributed to the differences among them. Caregivers in Western societies regularly attribute meaning to their infants' expressions of affect (e.g., Charlesworth, 1982; Johnson, Emde, Pannabecker, Stenberg, \& Davis, 1982; Lewis \& Michalson, 1983; Newson, 1979; and Trevarthan, 1979). Infants may be less inclined toward expression through another system when a caregiver is particularly successful in attributing meaning to their emotional expressions. Also, mastering the phonology of language depends on maturation. Children who are not ready to analyze the sounds of speech may, instead, increase in emotional lability.

The second point is that the early word learners who spent more time in neutral states certainly expressed positive and negative affect. In fact, the early word learners and later word learners did not differ in their affect at 9 months (Bloom et al., 1986). However, after 9 months, some infants increased in frequency of emotional expression while other infants began to use words. In infantcaregiver interaction, only some minimal level of emotional expression may be necessary to sustain intersubjectivity, and may be under the infant's control from an early age (Sroufe, 1979; Tronick, Als, \& Adamson, 1979). Also, mothers have been shown to discourage the frequency of their infants' emotional expressions in the context of their socialization practices (Malatesta \& Haviland, 1982). Thus, less frequent emotional expression can be associated with learning words, without sacrifice to intersubjectivity.

Because the data reported here were correlational, causal direction cannot be assumed. The relation between affect and language learning probably results from several factors and we have argued for the role played by cognitive process in these developments. A second possible influence on the relation between affect and language learning is underlying temperament. Because the study reported here concerned individual differences between the children in their affect expression, which were associated with differences in their language learning, the results are relevant to the study of temperament. Beginning with Allport's (1937, p. 54) definition of temperament as "an individual's emotional nature, including . . . quality . . f fluctuation and intensity in mood," the idea that emotionality is a function of temperament has been fundamental in temperament theory and research (Buss \& Plomin, 1986; Goldsmith \& Campos, 1982; Rothbart, 1986). We do not have independent measures of temperament for the infants we studied. However, we expect that both factors, cognition and temperament, covaried in their influence on the children's language learning.

The results reported here indicate that neutral affect supports early language learning, in particular. The amount of neutral affect may not be the relevant variable for children who talk later, having had the benefit of further maturation and more exposure to words for their language learning. Neither the frequency of emotional expression nor time spent in neutral affect predicted the frequency of words at the language achievements. Thus, the differences among the infants were associated with age of language achievement, and not with talking more or saying more different words. We would expect, however, that when equated for age, the children who made the transition earlier were ahead of those who made the transition later-on these quantitative measures as well as on other more qualitative measures as, for example, they were with the transition to multiword speech.

To conclude, the meaning of language is not transparent in its forms, as is the case with affect, but depends, instead, on acts of expression and interpretation. Such actions entail certain cognitive capacities. These include, at the least, accessing knowledge from memory in relation to the data of perception for representation in the contents of states of mind, and recalling and recognizing words that express those contents (Bloom \& Beckwith, 1986). The results of the present study suggest that neutral affect supports the reflective stance that such processes require for early word learning.

\section{References}

Aarsleff, H. (1976). An outline of language-origins theory since the Renaissance. In S. Harnad, $H$. Steklis, \& J. Lancaster (Eds.), Origins and evolution of language and speech (pp. 4-13). New York: Annals of the New York Academy of Sciences (Vol. 280).

Adamson, L., \& Bakeman, R. (1982). Affectivity and reference: Concepts, methods, and techniques in the study of communication development of 6- to 18-month-old infants. In T. Field \& A. Fogel (Eds.), Emotion and early interaction (pp. 213-236). Hillsdale, NJ: Erlbaum.

Allport, G. (1937). Personality: A psychosocial interpretation. New York: Holt.

Bloom, L. (1973). One word at a time: The use of single word utterances before syntax. The Hague: Mouton. 
Bloom, L. (1981). Language development in relation to cognition. In R. Stark (Ed.), Language behavior in infancy and early childhood (pp. 395-398). New York: Elsevier/North Holland.

Bloom, L., \& Beckwith, R. (1986). Intentionality and language development. Unpublished manuscript.

Bloom, L., Beckwith, R., \& Capatides, J. (1987). Developments in the expression of affect. Manuscript submitted for publication.

Bloom, L., Beckwith, R., Capatides, J., \& Hafitz, J. (1987). Expression through affect and words in the transition from infancy to language. In $P$. Baltes, D. Featherman, \& R. Lerner (Eds.), Life-span development and behavior (Vol. 8). Hillsdale, NJ: Erlbaum.

Bloom, L., \& Wikstrom, P. (1987, July). The role of temperament in language development. Paper presented at the meeting of the International Congress for the Study of Child Language, Lund, Sweden.

Brazelton, T. (1979). Evidence of communication in neonatal behavioral assessment. In M. Bullowa (Ed.), Before speech: The beginning of interpersonal communication (pp. 79-88). Cambridge: Cambridge University Press.

Buss, A., \& Plomin, R. (1986). The EAS approach to temperament. In R. Plomin \& J. Dunn (Eds.), The study of temperament: Changes, continuities, and challenges (pp. 67-79). Hillsdale, NJ: Erlbaum.

Campos, J., Barret, K., Lamb, M., Goldsmith, H., \& Stenberg, C. (1983). Socioemotional development. In M. M. Haith \& J. J. Campos (Eds.), P. H. Mussen (Series Ed.), Handbook of child psychology: Vol.2. Infancy and developmental psychobiology (pp. 783-915). New York: Wiley.

Charlesworth, W. (1982). An ethological approach to research on facial expressions. In C. Izard (Ed.), Measuring emotions in infants and children (pp. 317-334). Cambridge: Cambridge University Press.

Darwin, C. (1913). The expression of the emotions in man and animals. New York: Appleton.

Dore, J. (1983). Feeling, form, and intention in the baby's transition to language. In R. Golinkoff (Ed.), The transition from prelinguistic to linguistic communication (pp. 167-190). Hillsdale, NJ: Erlbaum.

Dromi, E. (1982). In pursuit of meaningful words: A case study analysis of early lexical development. Unpublished doctoral dissertation, University of Kansas, Lawrence.

Ekman, P., \& Friesen, W. (1975). Unmasking the face: $A$ guide to recognizing emotions from facial cues. Palo Alto, CA: Consulting Psychologists Press.

Emde, R., Gaensbauer, T., \& Harmon, R. (1976). Emotional expression in infancy. New York: International Universities Press.
Goldsmith, H., \& Campos, J. (1982). Toward a theory of infant temperament. In R. Emde \& R. Harmon (Eds.), The development of attachment and affiliative systems (pp. 161-193). New York: Plenum.

Izard, C. (1986). Approaches to developmental research on emotion-cognition relationships. In D. Bearison \& H. Zimiles (Eds.), Thought and emotion: Developmental perspectives (pp. 2137). Hillsdale, NJ: Erlbaum.

Izard, C., Huebner, R., Risser, D., McGinnes, G., \& Dougherty, L. (1980). The young infant's ability to produce distinct emotion expressions. Developmental Psychology, 16, 132-140.

Johnson, W., Emde, R., Pannabecker, B., Stenberg, C., \& Davis, M. (1982). Maternal perception of infant emotion from birth through 18 months. Infant Behavior and Development, 5, 313-322.

Lamb, M., \& Campos, J. (1982). Development in infancy. New York: Random House.

Lewis, M., \& Michalson, L. (1983). Children's emotions and moods: Developmental theory and measurement. New York: Plenum.

Lifter, K., \& Bloom, L. (1986). Object play and the emergence of language. Manuscript submitted for publication.

Lock, A. (1978). The emergence of language. In A. Lock (Ed.), Action, gesture and symbol: The emergence of language (pp. 3-18). London: Academic Press.

Malatesta, C., \& Haviland, J. (1982). Learning display rules: The socialization of emotion expressions in infancy. Child Development, 53, 9911003.

McCarthy, D. (1954). Language development in children. In L. Carmichael (Ed.), Manual of child psychology (pp. 492-630). New York: Wiley.

Nelson, K. (1973). Structure and strategy in learning to talk. Monographs of the Society for Research in Child Development, 38(1-2, Serial No. 149).

Newson, J. (1979). The growth of shared understandings between infant and caregiver. In M. Bullowa (Ed.), Before speech: The beginnings of interpersonal communication (pp. 207-222). Cambridge: Cambridge University Press.

Olson, G., \& Sherman, T. (1983). Attention, learning, and memory in infants. In M. M. Haith \& J. J. Campos (Eds.), P. H. Mussen (Series Ed.), Handbook of child psychology: Vol. 2. Infancy and developmental psychobiology (pp. 10011080). New York: Wiley.

Piaget, J. (1981). Intelligence and affectivity: Their relationship during child development ( $\mathrm{T}$. Brown \& C. Kaegi, Trans.). Palo Alto, CA: Annual Reviews. (Original work published 1954)

Ricciuti, H., \& Poresky, R. (1972). Emotional behavior and development in the first year of life: An analysis of arousal, approach-withdrawal, 


\section{Child Development}

and affective responses. In A. Pick (Ed.), Minnesota symposium on child psychology (Vol. 6, pp. 69-96). Minneapolis: University of Minnesota Press.

Rispoli, M. (1986). The development of the transitive/intransitive distinction: The conceptual and semantic origins. Unpublished doctoral dissertation, Teachers College, Columbia University.

Rothbart, M. (1986). Longitudinal observation of infant temperament. Developmental Psychology, 22, 356-365.

Sroufe, A. (1979). Socioemotional development. In J. Osofsky (Ed.), The handbook of infant development (pp. 462-516). New York: Wiley.

Sroufe, A. (1984). The organization of emotional development. In K. Scherer \& P. Ekman (Eds.), Approaches to emotion (pp. 109-128). Hillsdale, NJ: Erlbaum.

Stechler, G., \& Carpenter, G. (1967). A viewpiont on early affective development. In J. Hellmuth (Ed.), Exceptional infant: The normal infant (Vol. 1, pp. 164-189). Seattle: Special Child Publications.

Stein, N., \& Jewett, J. (1986). A conceptual analysis of the meaning of basic negative emotions: Implications for a theory of development. In C. Izard \& P. Read (Eds.), Measuring emotions in infants and children (Vol. 2, pp. 238-267). Cambridge: Cambridge University Press.

Stern, D. (1977). The first relationship. Cambridge, MA: Harvard University Press.

Stern, D., Barnett, R., \& Spieker, S. (1983). Early transmission of affect: Some research issues. In J. Call, F. Galenson, \& R. Tyson (Eds.), Frontiers of infant psychiatry (pp. 74-84). New York: Basic.

Stern, W., \& Stern, C. (1907). Die Kindersprache. Leipzig: Barth.

Trevarthan, C. (1979). Communication and cooperation in early infancy: A description of primary intersubjectivity. In M. Bullowa (Ed.), Before speech: The beginning of interpersonal communication (pp. 321-347). Cambridge: Cambridge University Press.

Tronick, E., Als, H., \& Adamson, L. (1979). Structure of early face-to-face communicative interactions. In M. Bullowa (Ed.), Before speech: The beginning of interpersonal communication (pp. 321-347). Cambridge: Cambridge University Press.

Wozniak, R. (1986). Notes toward a co-constructive theory of emotion-cognition relationships. In D. Bearison \& H. Zimiles (Eds.), Thought and emotion: Developmental perspectives (pp. 3964). Hillsdale, NJ: Erlbaum. 